\title{
BK calcium-activated potassium channels regulate circadian behavioral rhythms and pacemaker output
}

\author{
Andrea L Meredith ${ }^{1,4}$, Steven W Wiler ${ }^{1}$, Brooke H Miller ${ }^{2}$, Joseph S Takahashi ${ }^{2}$, Anthony \\ A Fodor ${ }^{1}$, Norman F Ruby ${ }^{3}$, and Richard W Aldrich ${ }^{1}$ \\ ${ }^{1}$ Department of Molecular and Cellular Physiology and Howard Hughes Medical Institute, \\ Stanford University, Stanford, California 94305, USA \\ 2 Department of Neurobiology and Physiology and Howard Hughes Medical Institute, \\ Northwestern University, Evanston, Illinois 60208, USA \\ ${ }^{3}$ Department of Biological Sciences, Stanford University, Stanford, California 94305, USA
}

\begin{abstract}
Spontaneous action potentials in the suprachiasmatic nucleus $(\mathrm{SCN})$ are necessary for normal circadian timing of behavior in mammals. The SCN exhibits a daily oscillation in spontaneous firing rate (SFR), but the ionic conductances controlling SFR and the relationship of SFR to subsequent circadian behavioral rhythms are not understood. We show that daily expression of the large conductance $\mathrm{Ca}^{2+}$-activated $\mathrm{K}^{+}$channel (BK) in the $\mathrm{SCN}$ is controlled by the intrinsic circadian clock. BK channel-null mice $\left(\mathrm{KCnmal}^{-1-}\right)$ have increased SFRs in SCN neurons selectively at night and weak circadian amplitudes in multiple behaviors timed by the SCN. $\mathrm{Kcnmal}^{-1-}$ mice show normal expression of clock genes such as Arntll (Bmall), indicating a role for BK channels in SCN pacemaker output, rather than in intrinsic time-keeping. Our findings implicate BK channels as important regulators of the SFR and suggest that the SCN pacemaker governs the expression of circadian behavioral rhythms through SFR modulation.
\end{abstract}

Many physiological processes are regulated over the day-night cycle, and the circadian system has proven amenable for studying the effect of single gene mutations on physiology and behavior, even in complex mammalian systems. A number of strong mutant circadian phenotypes have been identified by forward and reverse genetics, ranging from changes in period length to complete arrhythmicity of the pacemaker and behavioral outputs1. Most of these mutations affect the function of the core clock mechanism, a cell-autonomous transcriptional network driven by interactions between positive and negative feedback loops of the activators CLOCK and BMAL1 and the repressors PER1-3, CRY1-2 and REV$\mathrm{ERB} \alpha$ (refs. 2,3). Recent evidence suggests that this molecular clock directly or indirectly controls the expression of transcripts involved in the generation of rhythmic cellular processes and output behaviors4, 5 .

In mammals, lesion and transplantation studies have localized the circadian clock to the suprachiasmatic nucleus (SCN) of the hypothalamus6 ${ }^{-} 8$. The SCN has a number of rhythmic outputs, which are conveyed to downstream target organs for regulation of

Correspondence should be addressed to A.L.M. (ameredith@ som.umaryland.edu).

${ }^{4}$ Present address: Department of Physiology, University of Maryland School of Medicine, 655 West Baltimore Street, Baltimore, Maryland 21201, USA.

\section{COMPETING INTERESTS STATEMENT}

The authors declare that they have no competing financial interests. 
behaviors such as feeding, mating, activity and sleep9. Information about the environmental light-dark cycle is transmitted directly to the $\mathrm{SCN}$ pacemaker through the retinohypothalamic tract, but rhythmic outputs of the SCN persist even in the absence of light cues. In constant darkness, the SCN maintains an 24-h rhythm in gene transcription4, spontaneous action potential firing rate $(\mathrm{SFR})^{10-} 14, \mathrm{Ca}^{2+}$ oscillations ${ }^{15}$ and neuropeptide secretion ${ }^{16,17}$. However, the mechanisms generating these rhythmic SCN outputs and their translation into downstream behaviors are not well understood.

One such rhythmic SCN output, spontaneous action potential activity, is an important regulator of behavioral rhythms. Suppression of SCN action potentials by tetrodotoxin causes arrhythmicity of circadian outputs ${ }^{18,19}$. SCN neurons in vivo fire spontaneous action potentials in a time-dependent manner ${ }^{10}$. In dissociated cells in culture, about $50 \%$ of SCN neurons show circadian SFR oscillations, although their phases are not synchronized ${ }^{20}$. However, in acutely isolated slices where synaptic connectivity is preserved, the average SFR of SCN neurons is loosely synchronized, peaking at $\sim 8$ spikes per $\mathrm{s}$ in the middle of the subjective day and dropping to $<2.5$ spikes per $\mathrm{s}$ during the night ${ }^{11-14}$. Recent evidence suggests that this synchronization of SCN neuronal activity is important for the expression of behavioral rhythms ${ }^{21}$.

Potassium $\left(\mathrm{K}^{+}\right)$channels have been proposed as key regulators of the intrinsic circadian variation in excitability and SFR in mammalian $\mathrm{SCN}$ neurons ${ }^{22}$. A fast, delayed-rectifier $\mathrm{K}^{+}$ current has been identified that modulates SFR during the day ${ }^{23}$. However, a greater proportion of $\mathrm{K}^{+}$channels are active in SCN neurons at night, correlating with hyperpolarized membrane potentials and reduced input resistance ${ }^{24,25}$. The molecular identity of these night currents are currently unknown, but Kcnmal, a rhythmically expressed transcript in the $\mathrm{SCN}$ encoding the large conductance $\mathrm{Ca}^{2+}$-activated $\mathrm{K}^{+}$channel (BK), is highly expressed during the subjective night ${ }^{4}$, when SFR is low. The identification of an ion channel whose transcription oscillates over the circadian cycle suggests a link between the molecular clock transcription pathways and SCN electrical output.

In this study, we provide evidence for an essential role for BK channels in circadian function. Deletion of Kcnmal abolishes the low SFR at night in SCN neurons and degrades circadian behavioral rhythms by altering pacemaker output.

\section{RESULTS}

\section{Expression of BK channels over the circadian cycle}

SCNs were harvested at 4-h intervals from wild-type mice entrained to a standard 12:12 $\mathrm{h}$ light-dark cycle. BK channels were clearly upregulated at night (Fig. 1a,b). Wild-type mice maintained in constant darkness also demonstrated a circadian peak in BK expression at 20 h, consistent with Kcnmal transcript rhythmicity ${ }^{4}$. These results show that BK expression in the SCN is intrinsically regulated, as light is not required for protein rhythmicity. To test this further, we examined BK expression in a mouse mutation of the core clock gene Per2 (ref. 26). Per 2 mice had a shorter $(\sim 22 \mathrm{~h})$ circadian period in constant darkness before becoming arrhythmic. In SCNs from Per 2 mice housed in constant darkness for $5 \mathrm{~d}$, the peak of BK expression was consequently shifted earlier, to $16 \mathrm{~h}$ (Fig. 1b). These data suggest that molecular clock transcription pathways direct SCN excitability through the daily regulation of BK channel expression.

The SCN consists of bilaterally symmetric nuclei in the ventral hypothalamus, adjacent to the third ventricle. Coronal brain slices showed the highest anti-BK immunoreactivity on cell membranes in the SCN (Fig. 1c). Although neurons in the SCN are heterogenous with respect to neurotransmitter identity, firing properties and intrinsic rhythmicity $20,27^{-29}$, BK 
channels were uniformly expressed. At night $(20 \mathrm{~h})$, BK protein was expressed across the dorsal-ventral and rostral-caudal axes of the SCN. Adjacent hypothalamic nuclei receiving efferent projections from the $\mathrm{SCN}$, as well as afferents conveying direct photic input via the retinohypothalamic tract, did not show appreciable BK staining. The paucity of staining in the surrounding hypothalamus indicated that the daily rhythm in protein levels on western blots was derived from $\mathrm{BK}$ channels in the $\mathrm{SCN}$, since no additional hypothalamic regions began to express BK channels at $20 \mathrm{~h}$ versus $6 \mathrm{~h}$. Accordingly, BK staining was more intense throughout the SCN at $20 \mathrm{~h}$ (Fig. 1c). High magnification images suggested that the augmented expression resulted from individual SCN neurons expressing greater levels of BK channels at $20 \mathrm{~h}$ compared to $6 \mathrm{~h}$.

\section{Circadian behaviors are less robust in $\mathrm{Kcnma1}^{-/-}$mice}

The rhythmicity of BK protein in the SCN suggests that these channels have an important role in circadian function. To reveal such a role, we examined the behavioral consequences of deleting Kcnmal ( $\mathrm{Kcnmal}^{--}$), the gene that encodes the pore-forming subunit of the BK channel. Kcnmal ${ }^{-1-}$ mice were previously generated by targeted mutation and were shown to lack BK currents ${ }^{30}$. We found that these mice showed normal gross neurological function and development (data not shown). Normal SCN and hypothalamus morphology was revealed by the neuronal marker neurofilament 200 (Fig. 1d). BK immunoreactivity was completely absent from $\mathrm{Kcnmal}^{-1-} \mathrm{SCN}$ sections (Fig. 1d) and from total soluble protein fractions on western blots (data not shown).

Circadian behavior was assessed in wild-type and $\mathrm{KCnmal}^{-1-}$ littermates by locomotor activity, which reflects the characteristics of pacemaker function, such as the circadian period and the amplitude of activity rhythms ${ }^{31}$. Wheel-running rhythms were recorded as activity counts per time (actograms). Wild-type and $\mathrm{Kcnmal}^{-1-}$ mice entrained normally to a standard light-dark cycle, showing consolidated locomotor activity at night (Fig. 2a,b; Table 1). To test the function of the intrinsic pacemaker, mice were placed in constant darkness. Using $\chi^{2}$ statistical analysis ${ }^{32}$, we found a dominant circadian periodicity in the distribution of both wild-type and $\mathrm{Kcnmal}^{-/-}$wheel-running activity (Fig. 2c,d). The average period length $(\tau)$ in $\mathrm{Kcnmal}^{-1-}$ mice was $\sim 10$ min longer than that in the wild type (Table $1 ; P=0.02$ ). Circadian amplitude, the relative power of the dominant circadian component of a Fourier transform of the activity data ( $0.040-0.042$ cycles per $\mathrm{h})$, quantifies the robustness of this rhythmicity. On both an entrained light-dark cycle and under freerunning conditions (constant darkness), the circadian amplitude of locomotor activity in $\mathrm{KCnmal}^{-1-}$ mice was decreased compared to that in wild-type mice (Fig. 2e,f; Table 1). We conclude from these data that BK channels are important for the robustness of circadian wheel-running activity.

\section{Kcnma1 $^{-1-}$ mice have altered pacemaker function}

Circadian rhythms are generated by three basic components-input pathways to the pacemaker that mediate entrainment to exogenous cues; the pacemaker, which generates the circadian rhythm; and the pacemaker output, which conveys clock parameters to circadianly regulated behaviors ${ }^{1}$. Kcnmal ${ }^{-/-}$mice showed less overall wheel-running activity in both light-dark and constant darkness conditions than wild-type littermates (Fig. 2g; Table 1). Given that BK channels are necessary for normal coordinated locomotor function and that $\mathrm{Kcnmal}^{-1-}$ mice are ataxic ${ }^{30,33}$, we measured home-cage activity, a behavior that is less reliant on coordinated locomotion. Using motion sensors, we recorded cage activity (Fig. 3) and found that $\mathrm{Kcnmal}^{-1-}$ mice were, in fact, hyperactive, exhibiting increases of $74 \%$ and $59 \%$ in light-dark and constant darkness, respectively, compared to wild-type mice (FVB/ NJ, Fig. 3e and Table 1; light-dark, $P=0.02$; constant darkness, $P=0.01$ ). However, this hyperactivity seemed to be strain sensitive, as C57BL/6J $\mathrm{Kcnmal}^{-1-}$ mice did not 
demonstrate different average daily counts for home-cage activity (Table 1; light-dark, $P=$ 0.52 ; constant darkness, $P=0.26$ ). Because $\mathrm{Kcnmal}^{-/-}$mice did not show diminished home-cage locomotor activity, we further examined the circadian rhythmicity of this behavior in both strain backgrounds.

Home-cage activity was also entrainable to a light-dark cycle. Wild-type and $\mathrm{Kcnmal}^{-/-}$ mice made most of their movements in the dark period (70\% and $79 \%$ of the total daily activity, respectively; FVB/NJ, Fig. 3a,b and Table 1). Unlike the results from wheel running, the average circadian amplitude in light-dark was not different between genotypes (Table $1 ; P=0.56$ ). Nevertheless, home-cage rhythms in constant darkness were degraded in the same manner as wheel-running rhythms. We found that 0 of 12 wild-type and 1 of 10 $\mathrm{Kcnmal}^{-/-}$mice were arrhythmic, as determined by $\chi^{2}$ periodogram analysis. Mice of both genotypes showed a dominant circadian rhythm with similar period lengths (Table 1; $P=$ 0.46), although $\tau$ was slightly longer in $\mathrm{Kcnmal}^{-1-}$ mice on other strain backgrounds. The major difference between $\mathrm{Kcnmal}^{-1-}$ and wild type mice was an $88 \%$ reduction in the circadian amplitude of activity in constant darkness (Fig. 3c,d and Table $1 ; P=10^{-6}$ ). Despite the fact that FVB/NJ Kcnmal ${ }^{-1-}$ mice were hyperactive, nonhyperactive C57BL/6J mutants showed the same circadian phenotype (Table 1). In addition, actogram plots revealed an expansion of the active period in $\mathrm{Kcnmal}^{-1-}$ mice. This was reflected as an increase in activity bouts per day (Fig. 3e) and an increase in $\alpha$, a metric quantifying the length of daily consolidated activity (Fig. 3a,b and Table $1 ; P=10^{-3}$ ). Taken together, alterations in the amplitude of home-cage activity and the expansion of the active period suggest that pacemaker function is altered.

To further localize the circadian defect, we performed additional behavioral manipulations to test the input to the pacemaker. If BK channels were involved in photic input to the clock, responses to light would be disrupted in $\mathrm{KCnmal}^{-/-}$mice. However, a 6-h advance of the light-dark cycle resulted in a similar number of days to re-entrainment (Fig. 4a,b and Table $1 ; \mathrm{FVB} / \mathrm{NJ}, P=0.30 ; \mathrm{C} 57 \mathrm{BL} / 6 \mathrm{~J}, P=0.70)$. Phase response curves were not determined in $\mathrm{Kcnmal}^{-1-}$ mice because only a small number of these mice had clean activity onsets suitable for light pulsing. However, light pulses did result in average phase delays in both wild-type and $\mathrm{Kcnmal}^{-1-}$ mice (Fig. 4c,d and Table 1; FVB/NJ, $P=0.30 ; \mathrm{C} 57 \mathrm{BL} / 6 \mathrm{~J}, P=$ 0.28). On the basis of these results, as well as the lack of BK expression in the retinohypothalamic tract, we rule out a role for BK channels in conveying light input to the pacemaker.

Mutations that alter the function of the intrinsic pacemaker affect the rhythmicity of multiple downstream physiological pathways, including locomotor activity, core body temperature $\left(T_{\text {core }}\right)$ and spontaneous action potential activity in the SCN. We investigated $T_{\text {core }}$ using telemetry. Both wild-type and $\mathrm{Kcnmal}^{-1-}$ mice had rhythmic $T_{\text {core }}$ oscillations in constant darkness (Fig. 5a,b; wild-type range: $3.94 \pm 0.17{ }^{\circ} \mathrm{C}, n=7 ; \mathrm{Kcnmal}^{-1-}: 4.66 \pm 0.40{ }^{\circ} \mathrm{C}, n=$ $9 ; P=0.11$ ). The average $T_{\text {core }}$ was similar in mice of both genotypes (wild- type: $36.73 \pm$ $0.37{ }^{\circ} \mathrm{C}, n=7 ;$ Kcnmal $^{-/-}: 36.77 \pm 0.39{ }^{\circ} \mathrm{C}, n=6 ; P>0.05$ ), indicating that the loss of $\mathrm{BK}$ channels did not alter the homeostatic regulation of body temperature. Spectral separation of the $T_{\text {core }}$ components allowed us to isolate the circadian periodicity $(23-25 \mathrm{~h})$ from the noncircadian $T_{\text {core }}$ fluctuations associated with cage activity $(<3 \mathrm{~h})$. Although the circadian period of the temperature oscillation was intact (Table 1; $P=0.35$ ), $\mathrm{Kcnmal}^{-/-}$mice showed a $66 \%$ decrease in $T_{\text {core }}$ circadian amplitude compared to wild-type mice (Fig 5c,d and Table $1 ; P=0.01)$.

Although activity and temperature influence each other, these outputs rely on separate pathways downstream of the pacemaker. $T_{\text {core }}$ is ultimately regulated by the autonomic nervous system, and the poor wheel running of $\mathrm{Kcnmal}^{-/-}$mice reveals the dependence of 
this output pathway on the cerebellum (A.L.M. and R.W.A., unpublished data; and ref. 33). In summary, the three behaviors relying ultimately on different behavioral pathways downstream of the pacemaker-namely, wheel running, home-cage activity and core body temperature-all demonstrated a reduction in the robustness of circadian rhythmicity in $\mathrm{Kcnmal}^{-/-}$mice compared to wild-type mice. We conclude that loss of BK channels affects the function of the pacemaker, rather than the input or behavior-specific pathways, resulting in decreased circadian behavioral amplitude.

\section{Electrical activity is altered in $\mathrm{Kcnma1}^{-/-} \mathrm{SCN}$ neurons}

Circadian pacemaker function relies on action potentials in the SCN for the expression of downstream behavioral rhythms ${ }^{18}$. SCN neurons show a synchronous daily rhythm in SFR in hypothalamic slices, where the population average reflects the SFR rhythms in individual neurons ${ }^{11-14}$. We used single-unit extracellular recordings to determine the SFR of SCN neurons during the daytime activity peak or at night (Fig. 6a,b). Because BK channels were not restricted to any subregion of the SCN (Fig. 1c), SFRs from the entire nucleus were sampled. Acute slices prepared from the brains of wild-type and $\mathrm{Kcnmal}^{-1-}$ mice both exhibited a range of SFR frequencies (Fig. 6c,d; wild-type: 1.0-23.1 Hz; Kcnmal ${ }^{-1-}$ : 0.8$18.2 \mathrm{~Hz}$ ). There was no significant difference between mice from the two genotypes in the average SFRs at the daytime activity peak (Fig 6d; wild-type: $8.0 \pm 0.7 \mathrm{~Hz}, n=58$ neurons, 6 slices; Kcnmal $^{-1-}: 8.6 \pm 0.6 \mathrm{~Hz}, n=51$ neurons, 4 slices; $P=0.91$ ). At night, neurons from both wild-type and $\mathrm{KCnmal}^{-/-}$mice had decreased SFRs compared to those at their respective daytime peaks (Fig. 6d; day versus night: wild-type $P=10^{-19}, \mathrm{Kcnmal}^{-1-} P=$ $10^{-4}$ ), demonstrating that both genotypes express a circadian variation in the population averages of SFRs.

Although neurons from $\mathrm{Kcnmal}^{-/-}$mice seemed to maintain a daily oscillation in SFR, the amplitude was altered. Notably, the night-time average SFR of $\mathrm{Kcnmal}^{-1-}$ neurons was 2.5 times higher than wild type (Fig. 6d; wild-type: $2.5 \pm 0.2, n=111$ neurons, 5 slices; Kcnmal $^{-l-}: 6.4 \pm 0.3, n=110$ neurons, 4 slices; $P=10^{-12}$ ). The entire range of SFRs recorded from neurons in $\mathrm{Kcnmal}^{-/-}$mice was shifted higher, suggesting that the loss of BK channels affects most neurons in the population rather than a specific subset. We also found fewer detectable spontaneously firing neurons in the SCNs of wild-type mice at night than in the SCNs of $\mathrm{Kcnmal}^{-/-}$mice. Thus in the absence of BK channels, SCN neurons show increased activity at night and a subsequent alteration of the daily SFR rhythm. In Kcnmal $^{-1-}$ mice, the aberrant amplitude of SFR rhythms in the SCN may be the basis for the change in pacemaker function.

\section{Core clock transcript expression in $\mathrm{Kcnma1}^{-/-}$hypothalamus}

Alteration of the SFR may modify signaling pathways within the SCN and/or from the SCN to downstream nuclei in the brain. These changes could be reflected as differences in gene expression in the hypothalamus of $\mathrm{Kcnmal}^{-/-}$versus wild-type mice. We therefore examined whether the loss of BK channels resulted in altered transcript levels in the SCN and surrounding hypothalamic nuclei, using microarray analysis of gene expression. Blocks of ventral hypothalamus containing the SCN were harvested from wild-type and $\mathrm{Kcnmal}^{-/-}$ mice, in both light-dark and constant darkness conditions, at $20 \mathrm{~h}$ - the time of peak BK protein expression in wild-type mice in both conditions. Expression levels for each of the 45,100 transcripts on the array are reported in Supplementary Table 1 online.

The levels of all transcripts were compared in light-dark and constant darkness conditions (Fig. 7a,b). In both conditions, the expression profiles were nearly identical (wild-type versus $\mathrm{Kcnmal}^{-/-}, r^{2}=0.99$ for light-dark, $r^{2}=0.98$ for constant darkness). We concluded that deletion of BK channels has little systematic effect on gene expression. Furthermore, no 
broad transcriptional differences were revealed between light-dark versus constant darkness conditions at $20 \mathrm{~h}$ (Supplementary Table 2 online).

Although there were no large-scale transcriptional consequences of the loss of BK channels, the levels of individual transcripts could change. To examine this possibility, we calculated the ratio of the expression level in $\mathrm{Kcnmal}^{-/-}$mice to wild type for each transcript on the microarray (Supplementary Tables 1 and 3 online). Specifically, core clock transcripts such as Per1, Per2, Clock and Arntl (also known as Bmall/MOP3) showed similar expression levels in $\mathrm{Kcnmal}^{-/-}$mice and wild-type mice at $20 \mathrm{~h}$. Because its expression is in-phase with that of BK (ref. 34), we examined Arntl levels in detail by in situ hybridization. We found no major differences in Arntl expression in the SCNs of $\mathrm{Kcnmal}^{-1-}$ mice versus wild type over the circadian cycle (Fig. 7c,d). These data show that the degradation of circadian activity in $\mathrm{Kcnmal}^{-/-}$mice is not caused by gross alteration of Arntl rhythms or transcriptional pathways.

\section{DISCUSSION}

In this study, we demonstrated that BK channels are essential for robust circadian rhythmicity. The reduced circadian amplitude of multiple physiological processes suggests an antecedent role for BK channels in circadian pacemaking or in its output. Changes in the function of the central pacemaker may result from an alteration of the time-keeping mechanism or the integration and relay of the time signal output from the SCN. Several lines of evidence support the hypothesis that the primary circadian deficit in $\mathrm{Kcnmal}^{-/-}$mice is effected through changes in pacemaker output. $\mathrm{Kcnmal}^{-1-}$ mice showed a concomitant reduction of behavioral rhythm amplitude and expansion of the active phase $(\alpha)$, with little change in circadian period. Responses of $\mathrm{KCnmal}^{-1-}$ mice to light pulses also revealed a potentially meaningful exaggerated phase delay that is typical of pacemaker alterations (FVB/NJ, wild-type range: -0.71 to $-2.22 \mathrm{~h} ; \mathrm{Kcnmal}^{-/-}$range: $2.11,-4.64$ and $-5.12 \mathrm{~h}$; C57BL/6J, wild-type range: -1.60 to $-2.88 \mathrm{~h}$ and $\mathrm{Kcnmal}^{-1-}$ range: $-2.12,-3.10$ and $-3.13 \mathrm{~h}$ ). Circadian period, amplitude and phase are determined by the pacemaker, and in mammals, the SCN is thought to integrate these features into an overt activity rhythm ${ }^{35}$. Although the period and amplitude of activity rhythms are both essential indicators of the pacemaker state, they can vary independently of one another ${ }^{35}$. The significant decrease in circadian amplitude but relatively modest changes in circadian period in $\mathrm{Kcnmal}^{-1-}$ mice may be interpreted in this context as a requirement for BK channels in particular aspects of pacemaker function, such as output, reflecting an intermediate pacemaker state. In contrast, complete pacemaker dysfunction is manifested as outright arrhythmicity. Thus,

behaviorally, $\mathrm{Kcnmal}^{-1-}$ mice exhibit several key characteristics of altered pacemaker output. Notably, Slowpoke flies, which carry a mutation in the Drosophila melanogaster BK channel homolog, have degraded circadian locomotor rhythms, suggesting an evolutionary conservation of function ${ }^{36}$.

The epistatic relationship between the molecular clock mechanism and electrical activity in the pacemaker has been the subject of much debate recently. Mutants in Clock, Csnkle (tau) and Cry 1/2 produce altered SFR rhythms in the SCN (refs. 37-39), implying that SCN excitability is simply an output of the pacemaker. Indeed, we showed that BK expression is regulated by Per2. However, it is currently not known how separable the time-keeping and output components of the pacemaker are for the expression of circadian rhythms.

Manipulations of action potential rhythms or resting membrane potential, which were formerly considered merely as pacemaker outputs, can change the expression of PER1, PER2, BMAL1 and TIMELESS (refs. 22,40-42) and behavioral rhythms $42^{-45}$. In these cases, degradation of circadian behavior could be a direct consequence of either disruption of core clock gene expression or clock output (electrical activity). Both of these may be 
essential features of the pacemaker, as the time-keeping mechanism and conveyance of that consolidated signal are mutually required for normal circadian behavior. In $\mathrm{Kcnmal}^{-/-}$ mice, we did not find marked changes in the period or amplitude of Arntl expression in the $\mathrm{SCN}$, suggesting that the mechanism for circadian pacemaker alteration is not in the core clock gene-controlled time-keeping mechanism, but in the integration or relay of the time output from the SCN. However, we cannot preclude the possibility that there may be finer changes in clock gene expression in individual cells that are undetectable by Arntl in situ hybridization or by microarray analysis at $20 \mathrm{~h}$.

The mechanism of pacemaker output alteration in $\mathrm{Kcnmal}^{-1-}$ mice probably occurs through BK function in the SCN. BK channels are relatively restricted in their hypothalamic expression to the SCN. We showed that BK channels undergo a circadian oscillation in their SCN protein levels in the absence of light and also that Per2 mutants have a shortened expression profile, demonstrating a causative relationship between the intrinsic clock mechanism and the regulation of excitability. BK current amplitude also increases at night in Perl-expressing SCN neurons ${ }^{46}$. The consequence on SCN excitability of BK channel deletion is a disruption of the SFR rhythm. In $\mathrm{Kcnmal}^{-/-}$mice, SCN neurons have a selective increase in activity at night, correlating with the highest protein levels.

Consistent with our findings in $\mathrm{Kcnmal}^{-1-}$ mice, acute block of BK channels in the SCNs of wild-type mice during the day had no effect on daytime firing rates, even though the afterhyperpolarization was reduced and action potentials were broadened ${ }^{47}$. Other $\mathrm{K}^{+}$ channels, including a fast, delayed-rectifier current seem to control SFR during the day ${ }^{23}$. Blocking this current largely abolishes the day-night difference in SFR. In contrast, our recordings indicated that the SFR population average in $\mathrm{Kcnmal}^{-1-}$ mice is still significantly different between day and night $(8.6 \pm 0.6$ versus $6.4 \pm 0.3 \mathrm{~Hz}$, respectively, $P$ $=10^{-4}$ ). Microarray analysis did not provide evidence for the upregulation of any other $\mathrm{K}^{+}$ channels to compensate for the loss of BK (Supplementary Table 3), consistent with the lack of a compensatory $\mathrm{K}^{+}$current with acute block of BK channels in SCN neurons ${ }^{46}$. Thus there may be multiple mechanisms for controlling the SFR at night. The activation profile of BK channels, which are generally open during action potential repolarization and afterhyperpolarizations, may limit their influence on the SFR. Evidence that other $\mathrm{K}^{+}$ channels may also influence the SFR at night comes indirectly from the application of tetraethylammonium (TEA), a general blocker of voltage-gated $\mathrm{K}^{+}$channels. TEA depolarizes the membrane and increases input resistance ${ }^{24}$, and influencing these parameters could affect SFRs. It is likely that these effects would be mediated by $\mathrm{K}^{+}$channels active at resting membrane potentials, not by BK channels.

One critical link yet to be established is how action potential activity in the SCN is translated into downstream behavioral rhythms. In the most extreme cases, the silencing of activity altogether using tetrodotoxin or the expression of a constitutively open $\mathrm{K}^{+}$channel can cause behavioral arrhythmicity in rats and Drosophila ${ }^{18,42}$. SFR and behavioral rhythms are phase-locked ${ }^{10}$, suggesting that changing the SFR rhythm could perturb circadian activity. Our data demonstrate this crucial link as an alteration in the amplitudes of the SFR and behavioral rhythms. We propose that BK channels are partially responsible for suppressing high frequency firing at night and that this decrease in SFR is necessary for normal pacemaker output. It is likely that further analysis of the role of BK channels in the SCN will yield important clues about electrical activity and the mechanism of its influence on pacemaker function. 


\section{METHODS}

\section{Mice}

Wild-type and $\mathrm{Kcnmal}^{-/-}$littermates were generated on several backgrounds as noted, genotyped $^{30}$, and group-housed on a standard 12:12 h light-dark cycle until experimental measurements. Time $0 \mathrm{~h}$ is the beginning of the light cycle, and lights were turned off at 12 h. Mice ( $>1$ month old) then either remained on a light-dark cycle or were placed in constant darkness as indicated. Per2 mice $^{26}$ (B6.129S7-Per2 ${ }^{\text {tml } 1 \mathrm{Brd} / \mathrm{J})}$ were purchased from Jackson Laboratories. For experiments in which tissues were harvested in the dark portion of the circadian cycle (12-24 h) or in constant darkness, procedures were performed in the dark with dim red-light illumination until the optic chiasm was severed during brain dissection. All procedures were conducted in accordance with the animal care guidelines of Stanford and Northwestern Universities.

\section{Western blot analysis, immunohistochemistry and in situ hybridization}

A block of hypothalamus containing the SCN (approximately $2 \times 2 \times 1 \mathrm{~mm}$ ) was harvested at each time point from mice in light-dark or constant darkness conditions ( $5 \mathrm{~d})$. Four $\mu \mathrm{g}$ of total soluble protein from individual SCNs was loaded per lane, gels were transferred to nitrocellulose membrane, blocked and incubated with 1:10,000 L6.60 mouse $\alpha$-BK-channel monoclonal primary antibody ${ }^{48}$. Bands were visualized with 1:1,000 SuperSignal Dura reagent (Pierce) and quantified using the FluorChem 8800 (Alpha Innotech). Boxes of standard size were placed around each band, except in the case of the light-dark blots (in these, two BK-reactive bands were present and so both bands were quantified together)(Fig. 1a). BK band intensity counts were normalized to $\alpha$-tubulin (1:10,000 DM1 $\alpha$, Sigma $\mathrm{T}-9026)$ as a loading control and are presented as a proportion of the intensity at time $=0 \mathrm{~h}$. Two (Per2) or three (wild-type) replicates from independent tissue harvests were performed in each condition.

For immunohistochemistry, wild-type ( $n=4$ at $6 \mathrm{~h}$ and $n=3$ at $20 \mathrm{~h})$ or $\operatorname{Kcnmal}^{-/-}(n=2)$ brains were harvested from mice on a light-dark cycle at the indicated time points. Brains were coronally cryosectioned at $20 \mu \mathrm{m}$, blocked and incubated with 1:500 $\alpha$-BK rabbit polyclonal antibody (APC-021, Alamone Labs) and 1:100 monoclonal $\alpha$-neurofilament-200 (NF200, Novocastra Labs). Staining was visualized with 1:1,000 Alexa goat anti-rabbit 594 and anti-mouse 488 secondary antibodies (Molecular Probes) and mounted in Vectashield (Vector Labs).

In situ hybrizidation was performed as described ${ }^{49}$ with Arntl antisense oligos (5'-GGG TTG GTG GCA CCT CTC AAA GTT TTC ATG TGC TGA -3'). Brains from mice in constant darkness (14 d) were cryosectioned at $20 \mu \mathrm{m}$. Hybridization intensity for each SCN nucleus was background-subtracted and averaged together. Values were averaged from the SCNs of 8-15 sections from 4 mice of each genotype per time point.

\section{Locomotor behavior}

Wild-type and $\mathrm{Kcnmal}^{-1-}$ littermates were housed individually under indicated light-dark and constant darkness conditions. During constant darkness, cage changes were performed every 1-3 weeks with dim red-light illumination. Data from mice that died were discarded. Home cage activity was recorded by an infrared motion detector placed near the water bottle. Samples were obtained every 10 min using Dataquest A.R.T. software (Data Sciences). Wheel-running activity was measured with Chronobiology Kit software (Stanford Software Systems) ${ }^{50}$. 


\section{Temperature measurements}

Core body temperature was measured by implanting TA-F20 (Data Sciences) telemetry transmitters into the abdominal cavity of individually housed mice ( $>2$ months old). Mice recovered for 1 week on a standard light-dark cycle and were given $0.02 \mathrm{ml}$ Sulfatrim (HiTech Pharmacal) and $4 \mathrm{mg}$ Motrin per $\mathrm{ml}$ of drinking water. Mice were placed in constant darkness with nesting squares at an ambient room temperature of $21^{\circ} \mathrm{C}$. $T_{\text {core }}$ was sampled every 10 min with Dataquest A.R.T. (Data Sciences).

\section{Behavioral analysis and statistics}

Circadian behavior was quantified using ClockLab software (Actimetrics) running in Matlab v6.1 (Mathworks). Actograms were generated from 10-min activity bins, and total activity was determined by averaging daily activity sums in either the light-dark or the constant darkness conditions for the length of time shown in the behavioral records. The length of the circadian period, $\tau$, was calculated from locomotor activity in constant darkness, and $T_{\text {core }}$ was calculated as the highest $\chi^{2}$ peak $^{32}$. Mice with no $\chi^{2}$ value above a confidence interval of 0.001 were determined to be arrhythmic and were not included in further analysis. Circadian amplitude was calculated as the normalized peak of the relative power spectral density (rPSD) corresponding to the dominant $24-\mathrm{h}$ rhythm $(0.040-0.042$ cycles per $\mathrm{h}$ ) from a fast Fourier transform (FFT) of the activity or temperature data ${ }^{50}$. A Blackman-Harris window was applied to locomotor data but not to $T_{\text {core }}$ data. We determined re-entrainment values as the difference (in days) between manual regression fits of the activity onset in the initial light-dark cycle and the activity onset in the advanced (+6L) light-dark cycle. Phase shifts were similarly calculated as the number of hours between the onset regression fits before and after a 30-min light pulse delivered 4-h into the animal's subjective night (Circadian Time, CT,16). Due to high variability in activity onset in the constant darkness condition, CT16 was difficult to calculate reliably, and most $\mathrm{Kcnmal}^{-/-}$mice were not light-pulsed (FVB/NJ: 9 of 12 wild-type and 3 of $12 \mathrm{Kcnmal}^{-/-}$;C57BL/6J: 5 of 5 wild-type and $3 / 5 \mathrm{Kcnmal}^{-1-}$; Table 1). The parameter $\alpha$ was determined as the length of time a mouse had consolidated activity (inactivity gaps less than $1 \mathrm{~h}$ ) above its daily mean. For all experiments, group averages are reported \pm s.e.m., and statistical significance was determined by two-tailed Student's $t$-test with unequal variance at $P<0.05$.

\section{Electrophysiology}

Coronal sections (400-450 $\mu \mathrm{m}$ thick) were cut on a vibratome in $35^{\circ} \mathrm{C}$ oxygenated artificial cerebrospinal fluid (ACSF) containing $124 \mathrm{mM} \mathrm{NaCl}, 1.3 \mathrm{mM} \mathrm{MgSO}_{4}, 26 \mathrm{mM} \mathrm{NaHCO}_{3}$, $1.25 \mathrm{mM} \mathrm{KH}_{2} \mathrm{PO}_{4}, 3.3 \mathrm{mM} \mathrm{KCl}, 2.4 \mathrm{mM} \mathrm{CaCl}_{2}, 10 \mathrm{mM}$ dextrose and $0.16 \mathrm{mg} \mathrm{ml}^{-1}$ gentamicin (Sigma G-1397) at $\mathrm{pH}$ 7.4. Slices were cut from mice maintained on a light-dark cycle at time $1-3 \mathrm{~h}$ or $10-20 \mathrm{~h}$ to record day and night SFRs, respectively. One or two slices containing the $\mathrm{SCN}$ were recovered for $2 \mathrm{~h}$ at $35^{\circ} \mathrm{C}$, submerged in oxygenated ACSF, transferred to an interface chamber (BSC2, Scisys), and maintained at $35^{\circ} \mathrm{C}$ with constant perfusion for the duration of recording. Borosilicate glass electrodes (5-15 M $\Omega$ ) filled with saturated $\mathrm{NaCl}$ were used for recording. Single- or multiunit activity was collected with a Dam-80 amplifier (World Precision Instruments) and analyzed in pClamp 9.2 (Axon Instruments). Single units with signal-to-noise ratios $>2: 1$ were sorted by amplitude threshold-based statistics.

To verify that SFRs were derived from single neurons, we compared the average extracellular frequencies to SFRs recorded in loose-patch configuration, which allows for the direct measurement of single units. The values were similar overall (in the wild type, loose-patch average SFR was $7.8 \pm 0.8 \mathrm{~Hz}$ and range was $1.0-21.3 \mathrm{~Hz} ; n=33$ neurons, 2 slices), confirming that the extracellular SFRs reflect single neuron activity. 
In some recordings at night (mostly from wild-type slices), single units were hard to isolate from the background noise owing to the fact that fewer neurons were firing. In these cases, single units were determined by manually sorting spikes based on amplitude and waveform in pClamp. Each SFR represents 1.5-5 min of spontaneous activity from one static electrode placement in the SCN. SFRs for mice from each genotype were consolidated into single day or night averages as indicated.

\section{Gene expression microarrays}

Blocks of hypothalamus $(2 \times 2 \times 1 \mathrm{~mm})$ from 2-4 mice per genotype (light-dark or constant darkness) were combined for each independent microarray experiment. RNA was prepared by TRIzol (Invitrogen) and chloroform extractions, followed by RNeasy (Qiagen) column purification. First-strand synthesis was performed with 4-10 $\mu \mathrm{g}$ of pooled total RNA with the Genechip One-Cycle Target Labeling and Control Reagent package (Affymetrix), and $10 \mu \mathrm{g}$ of each wild-type or Kcnmal ${ }^{-l-}$ cRNA was hybridized to Affymetrix Murine Genome 4302.0 GeneChips at the Stanford University Microarray Core Facility. Data were normalized using Dchip software with default parameters. Additional details and validation are provided in Supplementary Methods online.

\section{Supplementary Material}

Refer to Web version on PubMed Central for supplementary material.

\section{Acknowledgments}

We would like to thank M. Barakat for assistance with circadian behavioral experiments, L. Baxter for assistance with animal care, and V. Cao for SCN slice preparation advice. We also thank D. Welsh for helpful comments on the manuscript. The work was supported by the Howard Hughes Medical Institute (R.W.A. \& J.S.T.) and the Mathers Foundation (R.W.A.).

\section{References}

1. King DP, Takahashi JS. Molecular genetics of circadian rhythms in mammals. Annu Rev Neurosci 2000;23:713-742. [PubMed: 10845079]

2. Reppert SM, Weaver DR. Coordination of circadian timing in mammals. Nature 2002;418:935-941. [PubMed: 12198538]

3. Hastings MH, Herzog ED. Clock genes, oscillators, and cellular networks in the suprachiasmatic nuclei. J Biol Rhythms 2004;19:400-413. [PubMed: 15534320]

4. Panda $S$, et al. Coordinated transcription of key pathways in the mouse by the circadian clock. Cell 2002;109:307-320. [PubMed: 12015981]

5. Ueda HR, et al. System-level identification of transcriptional circuits underlying mammalian circadian clocks. Nat Genet 2005;37:187-192. [PubMed: 15665827]

6. Stephan FK, Zucker I. Circadian rhythms in drinking behavior and locomotor activity of rats are eliminated by hypothalamic lesions. Proc Natl Acad Sci USA 1972;69:1583-1586. [PubMed: 4556464]

7. Moore RY, Eichler VB. Loss of a circadian adrenal corticosterone rhythm following suprachiasmatic lesions in the rat. Brain Res 1972;42:201-206. [PubMed: 5047187]

8. Ralph MR, Foster RG, Davis FC, Menaker M. Transplanted suprachiasmatic nucleus determines circadian period. Science 1990;247:975-978. [PubMed: 2305266]

9. Rusak B, Zucker I. Neural regulation of circadian rhythms. Physiol Rev 1979;59:449-526. [PubMed: 379886]

10. Yamazaki S, Kerbeshian MC, Hocker CG, Block GD, Menaker M. Rhythmic properties of the hamster suprachiasmatic nucleus in vivo. J Neurosci 1998;18:10709-10723. [PubMed: 9852606]

11. Green DJ, Gillette R. Circadian rhythm of firing rate recorded from single cells in the rat suprachiasmatic brain slice. Brain Res 1982;245:198-200. [PubMed: 6889453] 
12. Groos G, Hendriks J. Circadian rhythms in electrical discharge of rat suprachiasmatic neurones recorded in vitro. Neurosci Lett 1982;34:283-288. [PubMed: 6298675]

13. Shibata S, Oomura Y, Kita H, Hattori K. Circadian rhythmic changes of neuronal activity in the suprachiasmatic nucleus of the rat hypothalamic slice. Brain Res 1982;247:154-158. [PubMed: 7127113]

14. Inouye ST, Kawamura H. Persistence of circadian rhythmicity in a mammalian hypothalamic "island" containing the suprachiasmatic nucleus. Proc Natl Acad Sci USA 1979;76:5962-5966. [PubMed: 293695]

15. Ikeda $\mathrm{M}$, et al. Circadian dynamics of cytosolic and nuclear $\mathrm{Ca}^{2+}$ in single suprachiasmatic nucleus neurons. Neuron 2003;38:253-263. [PubMed: 12718859]

16. Earnest DJ, Sladek CD. Circadian rhythms of vasopressin release from individual rat suprachiasmatic explants in vitro. Brain Res 1986;382:129-133. [PubMed: 3768669]

17. Shinohara K, Honma S, Katsuno Y, Abe H, Honma K. Circadian release of amino acids in the suprachiasmatic nucleus in vitro. Neuroreport 1998;9:137-140. [PubMed: 9592063]

18. Schwartz WJ, Gross RA, Morton MT. The suprachiasmatic nuclei contain a tetrodotoxin-resistant circadian pacemaker. Proc Natl Acad Sci USA 1987;84:1694-1698. [PubMed: 3470750]

19. Earnest DJ, Digiorgio SM, Sladek CD. Effects of tetrodotoxin on the circadian pacemaker mechanism in suprachiasmatic explants in vitro. Brain Res Bull 1991;26:677-682. [PubMed: 1933388]

20. Welsh DK, Logothetis DE, Meister M, Reppert SM. Individual neurons dissociated from rat suprachiasmatic nucleus express independently phased circadian firing rhythms. Neuron 1995;14:697-706. [PubMed: 7718233]

21. Aton SJ, Herzog ED. Come together, right...now: synchronization of rhythms in a mammalian circadian clock. Neuron 2005;48:531-534. [PubMed: 16301169]

22. Lundkvist GB, Block GD. Role of neuronal membrane events in circadian rhythm generation. Methods Enzymol 2005;393:623-642. [PubMed: 15817316]

23. Itri JN, Michel S, Vansteensel MJ, Meijer JH, Colwell CS. Fast delayed rectifier potassium current is required for circadian neural activity. Nat Neurosci 2005;8:650-656. [PubMed: 15852012]

24. Kuhlman SJ, McMahon DG. Rhythmic regulation of membrane potential and potassium current persists in SCN neurons in the absence of environmental input. Eur J Neurosci 2004;20:11131117. [PubMed: 15305881]

25. de Jeu M, Hermes M, Pennartz C. Circadian modulation of membrane properties in slices of rat suprachiasmatic nucleus. Neuroreport 1998;9:3725-3729. [PubMed: 9858386]

26. Zheng B, et al. The $m P e r 2$ gene encodes a functional component of the mammalian circadian clock. Nature 1999;400:169-173. [PubMed: 10408444]

27. Antle MC, LeSauter J, Silver R. Neurogenesis and ontogeny of specific cell phenotypes within the hamster suprachiasmatic nucleus. Brain Res Dev Brain Res 2005;157:8-18.

28. Pennartz CM, De Jeu MT, Geurtsen AM, Sluiter AA, Hermes ML. Electrophysiological and morphological heterogeneity of neurons in slices of rat suprachiasmatic nucleus. J Physiol (Lond) 1998;506:775-793. [PubMed: 9503337]

29. van den Pol AN, Tsujimoto KL. Neurotransmitters of the hypothalamic suprachiasmatic nucleus: immunocytochemical analysis of 25 neuronal antigens. Neuroscience 1985;15:1049-1086. [PubMed: 2413388]

30. Meredith AL, Thorneloe KS, Werner ME, Nelson MT, Aldrich RW. Overactive bladder and incontinence in the absence of the BK large conductance $\mathrm{Ca}^{2+}$-activated $\mathrm{K}^{+}$channel. J Biol Chem 2004;279:36746-36752. [PubMed: 15184377]

31. Pittendrigh CS, Daan S. A Functional analysis of circadian pacemakers in nocturnal rodents. I. The stability and lability of spontaneous frequency. J Comp Physiol A Neuroethol Sens Neural Behav Physiol 1976;106:223-252.

32. Sokolove PG, Bushell WN. The chi square periodogram: its utility for analysis of circadian rhythms. J Theor Biol 1978;72:131-160. [PubMed: 566361]

33. Sausbier M, et al. Cerebellar ataxia and Purkinje cell dysfunction caused by $\mathrm{Ca}^{2+}{ }_{\text {-activated } \mathrm{K}^{+}}$ channel deficiency. Proc Natl Acad Sci USA 2004;101:9474-9478. [PubMed: 15194823] 
34. Honma S, et al. Circadian oscillation of BMAL1, a partner of a mammalian clock gene Clock, in rat suprachiasmatic nucleus. Biochem Biophys Res Commun 1998;250:83-87. [PubMed: 9735336]

35. Low-Zeddies SS, Takahashi JS. Chimera analysis of the Clock mutation in mice shows that complex cellular integration determines circadian behavior. Cell 2001;105:25-42. [PubMed: 11301000]

36. Ceriani MF, et al. Genome-wide expression analysis in Drosophila reveals genes controlling circadian behavior. J Neurosci 2002;22:9305-9319. [PubMed: 12417656]

37. Herzog ED, Takahashi JS, Block GD. Clock controls circadian period in isolated suprachiasmatic nucleus neurons. Nat Neurosci 1998;1:708-713. [PubMed: 10196587]

38. Nakamura W, Honma S, Shirakawa T, Honma K. Clock mutation lengthens the circadian period without damping rhythms in individual SCN neurons. Nat Neurosci 2002;5:399-400. [PubMed: 11953751]

39. Albus $\mathrm{H}$, et al. Cryptochrome-deficient mice lack circadian electrical activity in the suprachiasmatic nuclei. Curr Biol 2002;12:1130-1133. [PubMed: 12121621]

40. Yamaguchi S, et al. Synchronization of cellular clocks in the suprachiasmatic nucleus. Science 2003;302:1408-1412. [PubMed: 14631044]

41. Kuhlman SJ, Silver R, Le Sauter J, Bult-Ito A, McMahon DG. Phase resetting light pulses induce Perl and persistent spike activity in a subpopulation of biological clock neurons. J Neurosci 2003;23:1441-1450. [PubMed: 12598633]

42. Nitabach MN, Blau J, Holmes TC. Electrical silencing of Drosophila pacemaker neurons stops the free-running circadian clock. Cell 2002;109:485-495. [PubMed: 12086605]

43. Harmar AJ, et al. The VPAC(2) receptor is essential for circadian function in the mouse suprachiasmatic nuclei. Cell 2002;109:497-508. [PubMed: 12086606]

44. Cutler DJ, et al. The mouse VPAC2 receptor confers suprachiasmatic nuclei cellular rhythmicity and responsiveness to vasoactive intestinal polypeptide in vitro. Eur J Neurosci 2003;17:197-204. [PubMed: 12542655]

45. Nitabach MN, Sheeba V, Vera DA, Blau J, Holmes TC. Membrane electrical excitability is necessary for the free-running larval Drosophila circadian clock. J Neurobiol 2005;62:1-13. [PubMed: 15389695]

46. Pitts GR, Ohta H, McMahon DG. Daily rhythmicity of large-conductance $\mathrm{Ca}(2+)$-activated $\mathrm{K}(+)$ currents in suprachiasmatic nucleus neurons. Brain Res 2006;1071:54-62. [PubMed: 16412396]

47. Cloues RK, Sather WA. Afterhyperpolarization regulates firing rate in neurons of the suprachiasmatic nucleus. J Neurosci 2003;23:1593-1604. [PubMed: 12629163]

48. Misonou $\mathrm{H}$, et al. Immunolocalization of the $\mathrm{Ca}^{2+}$-activated $\mathrm{K}^{+}$channel Kcnma11 in axons and nerve terminals of mammalian brain and cultured neurons. J Comp Neurol 2006;496:289-302. [PubMed: 16566008]

49. Rattray, M.; Michael, GJ. Oligonucleotide probes for in situ hybridization. In: Wilkinson, DG., editor. In Situ Hybridization: A Practical Approach. 2. Oxford Univ. Press; Oxford: 1998. p. 23-67.

50. Siepka SM, Takahashi JS. Methods to record circadian rhythm wheel running activity in mice. Methods Enzymol 2005;393:230-239. [PubMed: 15817291] 

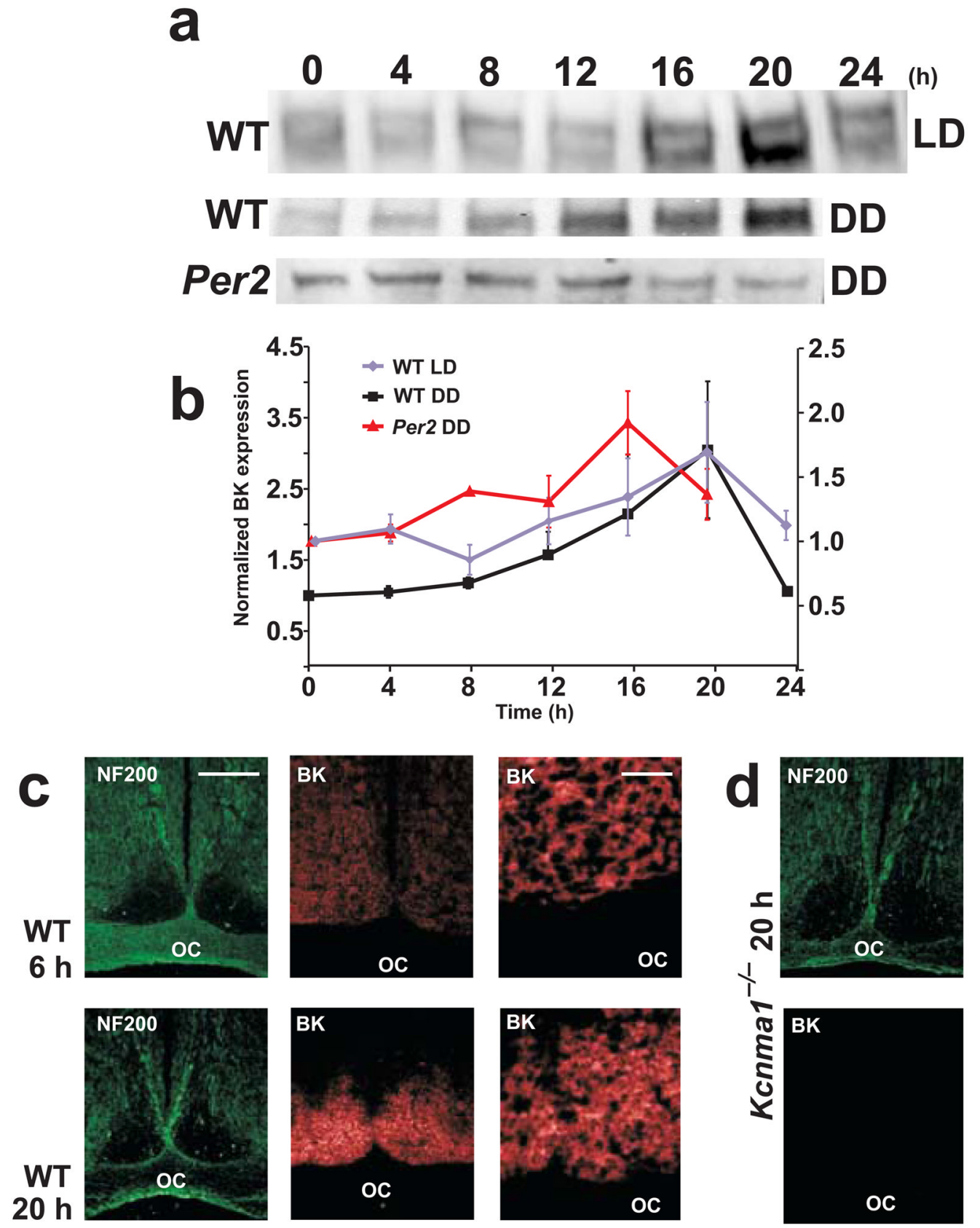

Figure 1.

BK channel expression in the SCN. (a) Representative $\alpha$-BK western blots from wild-type and Per 2 mice in light-dark and constant darkness conditions. Each lane contains protein from the SCN of an individual mouse at the indicated time point (light $=0-12 \mathrm{~h}$, dark $=12-$ $24 \mathrm{~h}$ ). (b) Normalized $\alpha$-BK signal \pm s.e.m. as a proportion of the value at time $=0 \mathrm{~h}$, for wild-type mice in constant darkness (left axis), and for wild-type mice in light-dark and Per2 mice in constant darkness (right axis) (different axes for ease of visualization of the relative differences within each condition. The wild-type 24-h constant darkness value is replotted from that at $0 \mathrm{~h}$. $(\mathbf{c}, \mathbf{d})$ Coronal tissue sections through the ventral hypothalamus. Neurofilament 200 (NF200, green) and $\alpha$-BK (red) staining of the same section harvested at $6 \mathrm{~h}$ or $20 \mathrm{~h}$. $\alpha$-BK panels were equivalently exposed $(500 \mathrm{~ms})$ for comparison of staining 
intensity. Scale bars: in c, $250 \mu \mathrm{m}$ in left and middle panels, $10 \mu \mathrm{m}$ in right panels; in d, 10 $\mu \mathrm{m}$. OC, optic chiasm; LD, light-dark; DD, constant darkness; WT, wild type. 

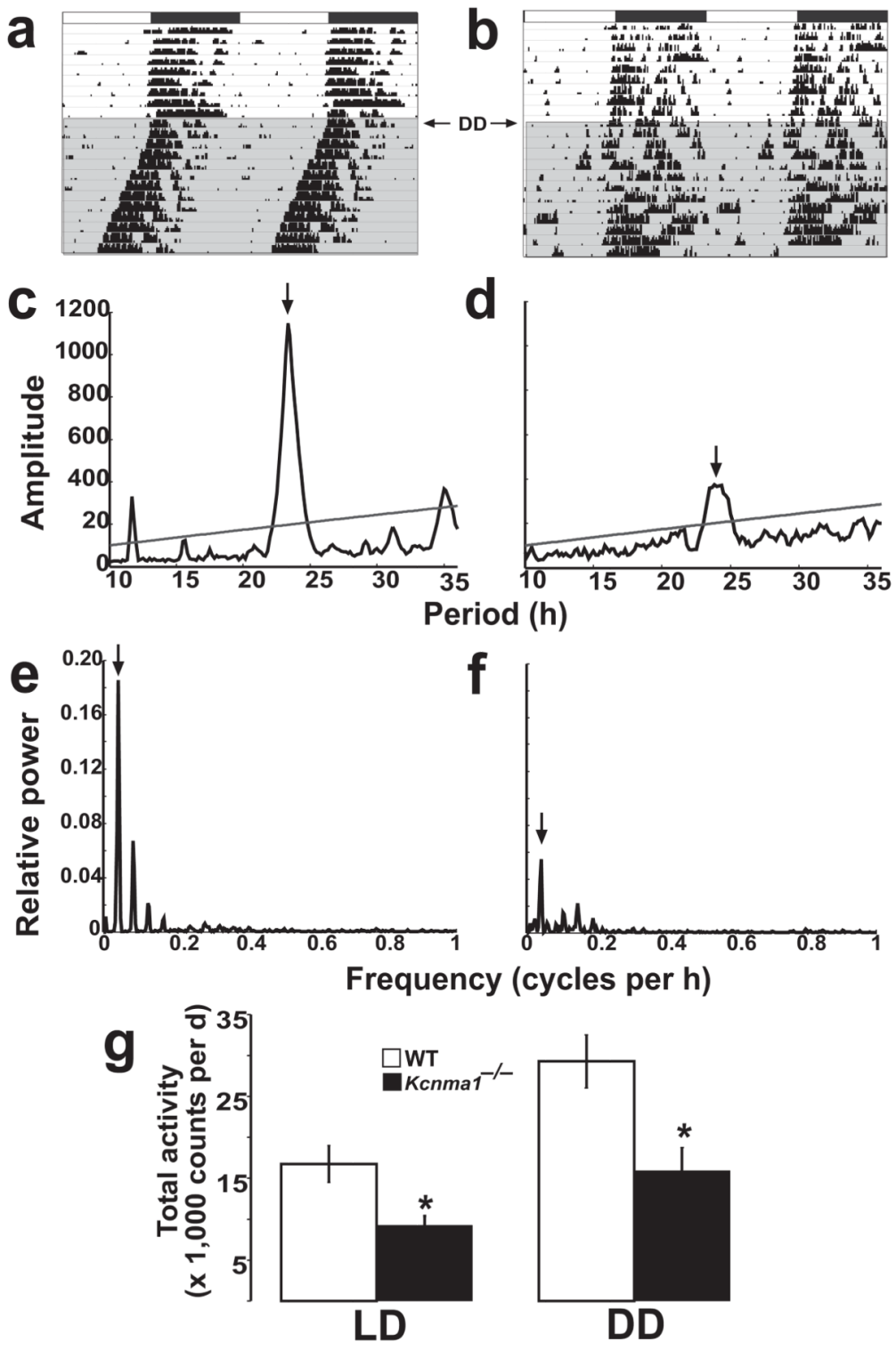

Figure 2.

Records of locomotor wheel-running activity. (a,b) Activity was measured from wild-type (a) and $\mathrm{Kcnmal}^{-/-}$(b) mice on an F2 (FVB/NJ) $\times(\mathrm{C} 57 \mathrm{BL} / 6 \mathrm{~J} / 129)$ strain background for 8 $\mathrm{d}$ in the light-dark condition and for $14 \mathrm{~d}$ in constant darkness (shaded area). Actograms are double-plotted on a 48-h axis; dark bars at top indicate lights out in the light-dark condition. $(\mathbf{c}, \mathbf{d}) \chi^{2}$ periodograms for wild-type (c) and $\mathrm{Kcnmal}^{-1-}(\mathbf{d})$ mice, generated from activity data in $\mathbf{a}$ and $\mathbf{b}$. There was a dominant circadian peak for both genotypes $(23.33 \mathrm{~h}$ and 23.83 $\mathrm{h}$, respectively). The line denotes the 0.001 confidence interval. Group averages for all circadian statistics are presented in Table 1. (e,f) Fourier analysis for wild-type (e) and $\mathrm{Kcnmal}^{-1-}$ (f) mice, obtained from activity data in $\mathbf{a}$ and $\mathbf{b}$. Arrows at 0.04 cycles per $\mathrm{h}$ correspond to the dominant 24-h rhythm. The amplitude of the circadian component was 0.168 for wild-type mice and 0.054 for $\mathrm{Kcnmal}^{-/-}$mice. (g) Averaged summed total wheelrunning activity per day \pm s.e.m. for wild-type and $\mathrm{Kcnmal}^{-/-}$mice in light-dark and constant darkness conditions. $* P<0.05$. 
a
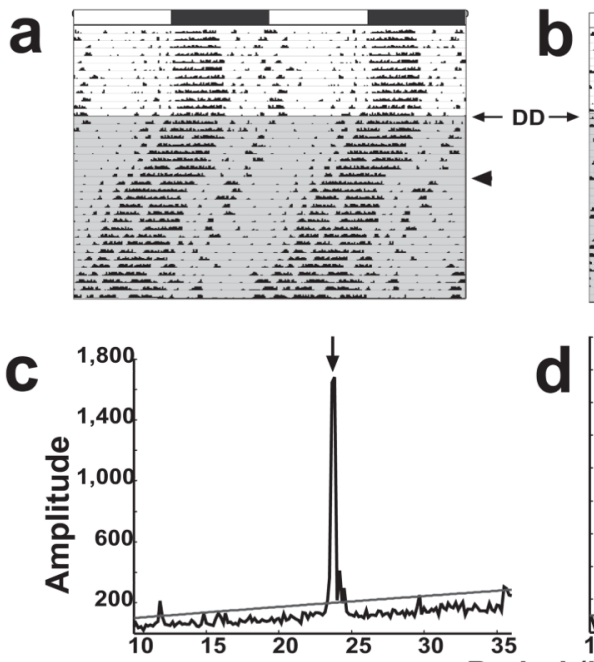

d

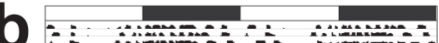
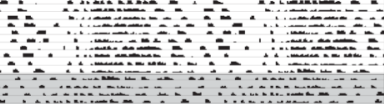

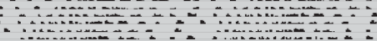

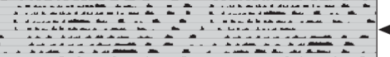

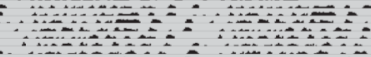

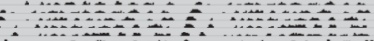

$+=$
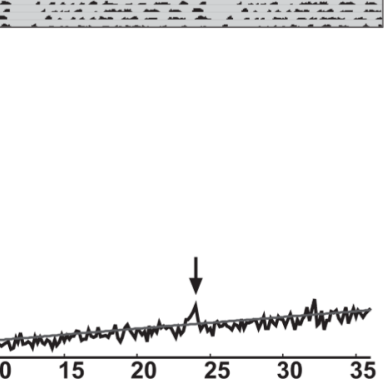

(h)
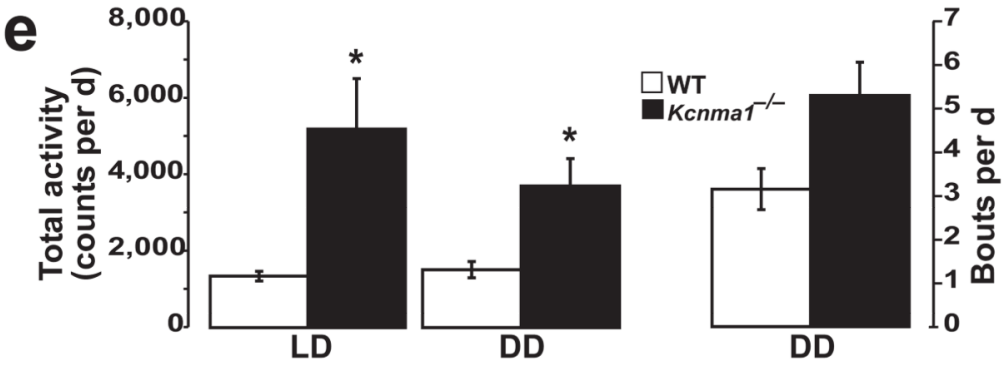

Figure 3.

Home-cage activity records. (a,b) Activity of FVB/NJ wild-type (a) and $\mathrm{Kcnmal}^{-1-}$ (b) mice was measured by motion sensors for $10 \mathrm{~d}$ in the light-dark condition and for $28 \mathrm{~d}$ in constant darkness (shaded area). Actograms are plotted as in Figure 2. Arrowheads indicate a 3-d gap in the data. (c,d) $\chi^{2}$ periodograms for wild-type (c) and $\mathrm{Kcnmal}^{-1-}$ (d) mice, plotted from the activity data. The dominant peaks are at $23.71 \mathrm{~h}$ and $24.00 \mathrm{~h}$, respectively. The line denotes the 0.001 confidence interval. (e) Averaged summed total activity per day \pm s.e.m. for wild-type and $\mathrm{Kcnmal}^{-1-}$ mice in light-dark and constant darkness conditions (left axis). Average daily activity bouts in constant darkness (right axis), defined as a continuous 60 -min period during which the activity stayed above 4 counts per min. ${ }^{*} P<$ 0.05 . 

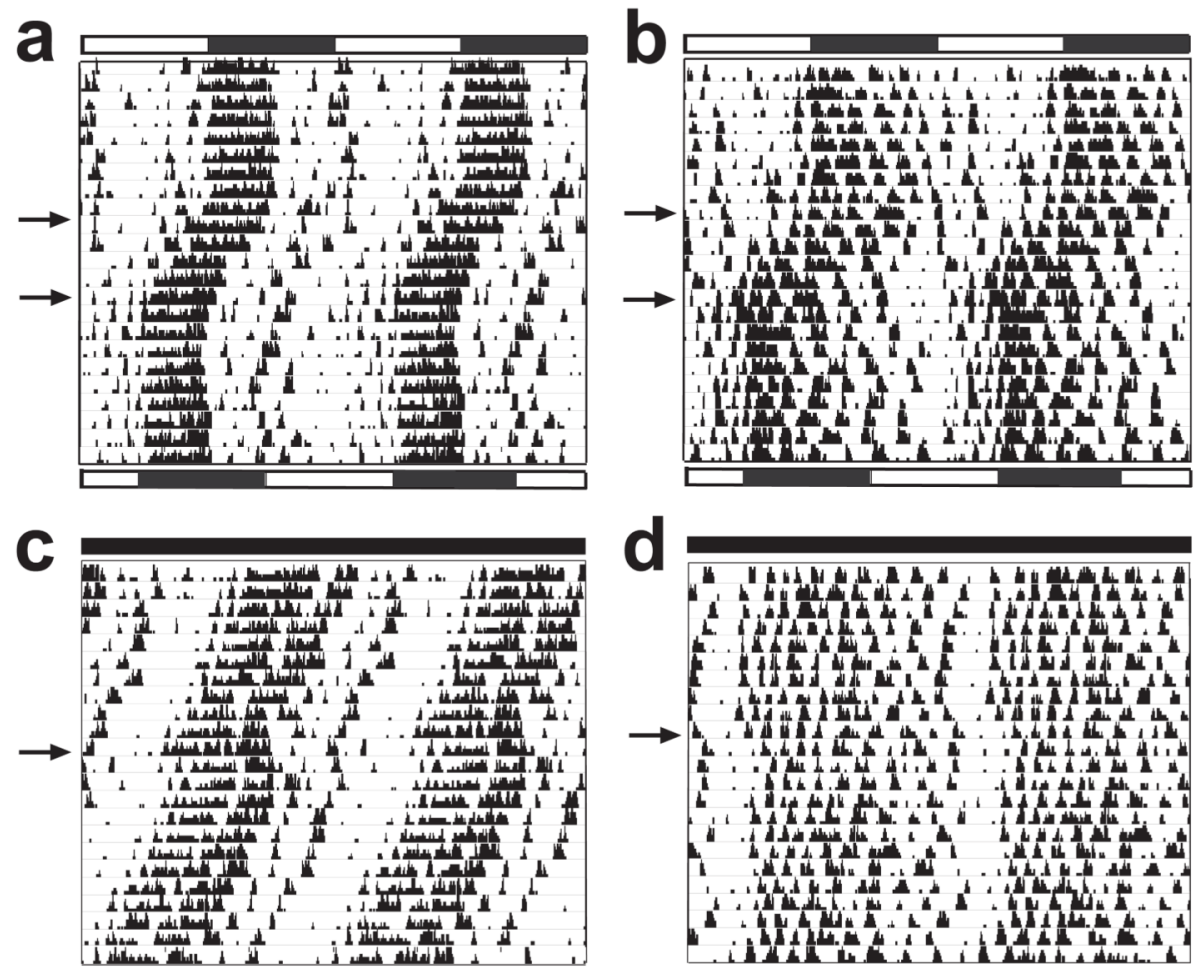

Figure 4.

Responses of $\mathrm{Kcnmal}^{-/-}$mice to light. (a,b) Motion sensor activity records of FVB/NJ wild-type (a) and $\mathrm{KCnmal}^{-1-}$ (b) mice. Mice were entrained to a standard light-dark cycle for 2 weeks (initial light-dark cycle denoted by bars at top). The light-dark cycle was then advanced $6 \mathrm{~h}$ during the light phase (top arrow, bars at bottom indicate new light-dark cycle). Bottom arrows mark stable entrainment after the light-dark cycle was advanced. (c,d) Motion sensor activity records from wild-type (c) and $\mathrm{Kcnmal}^{-/-}$(d) mice housed in constant darkness for 2 weeks. A 30-min light pulse was delivered $4 \mathrm{~h}$ after activity onset in subjective night (arrow). Group averages for re-entrainment and light pulses reported in Table 1. 
a

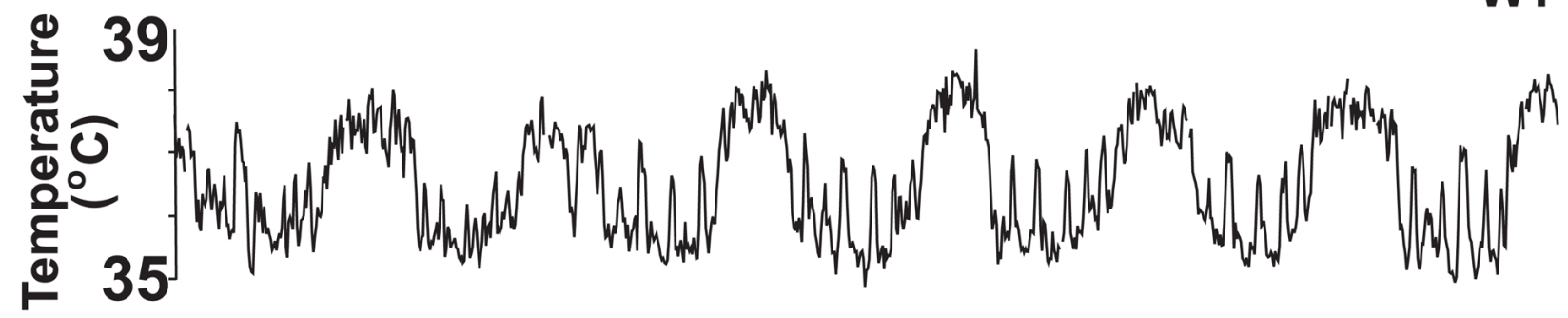

b
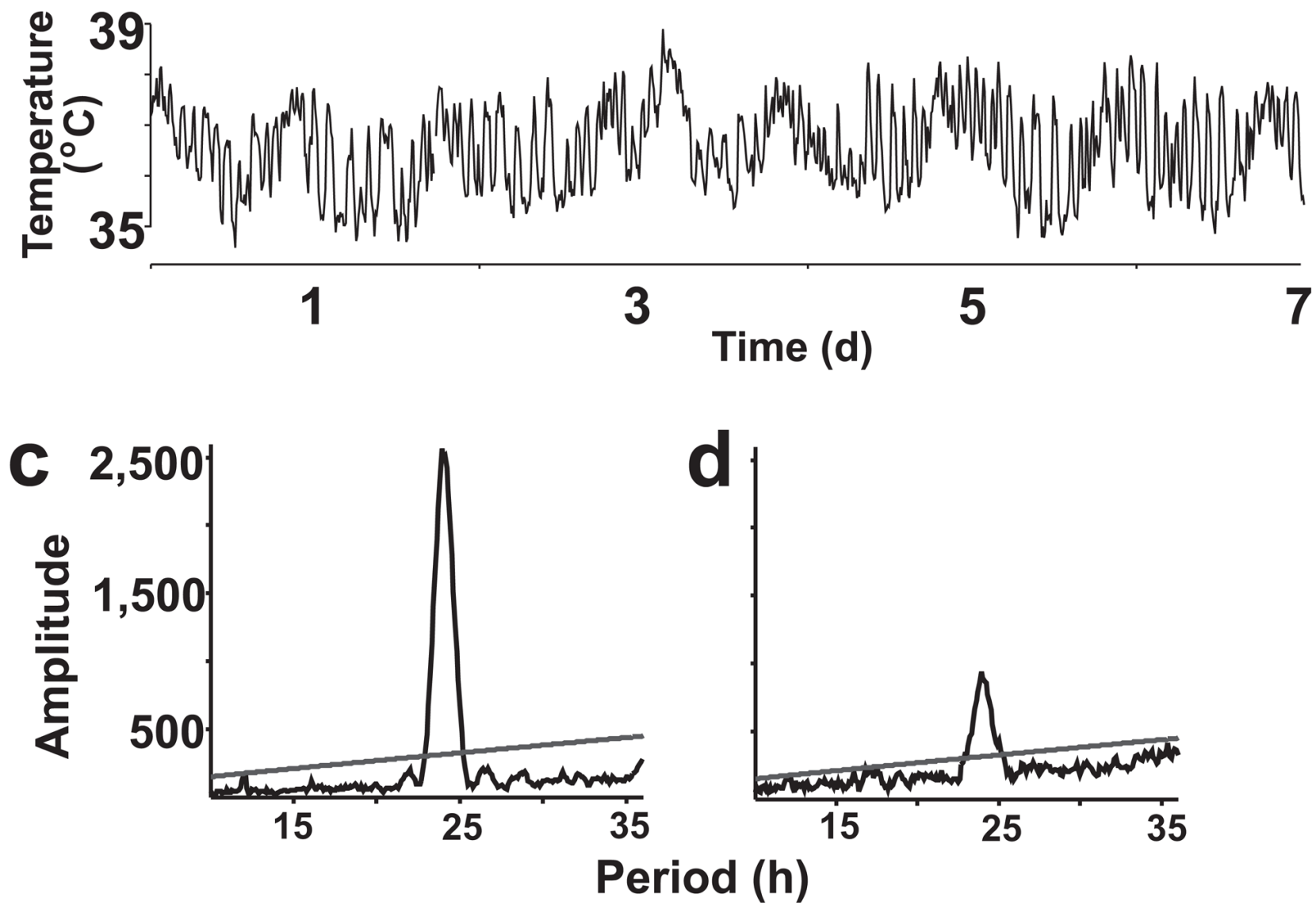

Figure 5.

Core body temperature $\left(T_{\text {core }}\right)$ measurements. (a,b) Following transmitter implantation, FVB/NJ wild-type and $\mathrm{KCnmal}^{-/}$mice were stably entrained to a standard light-dark cycle for 1 week and were placed in constant darkness for 1 week. (c,d) $\chi_{2}$ periodograms for wildtype (c) and $\mathrm{Kcnmal}^{-1-}$ (d) mice, plotted from the $T_{\text {core }}$ data obtained in constant darkness. The dominant peaks are at $23.90 \mathrm{~h}$ and $23.88 \mathrm{~h}$, respectively. The line denotes the 0.001 confidence interval. 

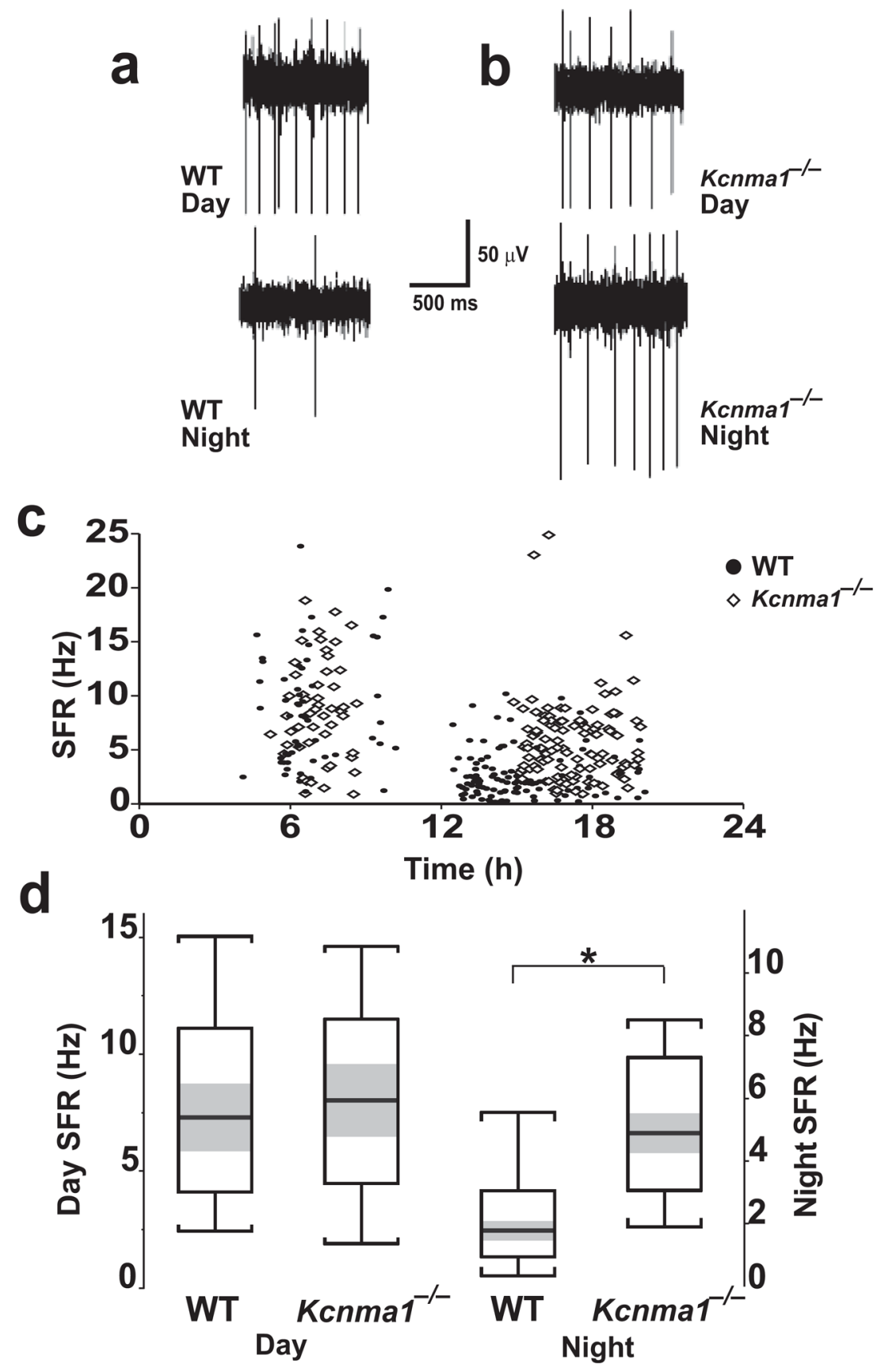

Figure 6.

SCN neuronal spontaneous firing rates (SFR). (a,b) Representative traces of single-unit activity from SCN neurons of FVB/NJ wild-type and $\mathrm{Kcnmal}^{-/-}$mice. Mice were housed in a standard light-dark cycle before slice preparation. Traces at top were obtained at the daytime SFR peak (4-8 h). Traces at bottom were obtained during the night (12-24 h). (c) Single-unit activity in wild-type and $\mathrm{Kcnmal}^{-/-}$mice. Each frequency measurement represents a single electrode placement monitoring the SFR continuously for 1.5-5 mins. (d) Box plots showing the 25 th and 75 th percentile limits (white) and $95 \%$ confidence intervals (gray) about the medians (thick line). Whiskers represent $1.5 \times$ interquartile range. Averages are reported in Results. Medians for subjective day were $7.3 \mathrm{~Hz}$ for wild type and $8.0 \mathrm{~Hz}$ for 
Kcnmal $^{-1-}$ neurons. At night, medians were $1.8 \mathrm{~Hz}$ for wild type and $4.9 \mathrm{~Hz}$ for the Kcnmal $^{-1-}$ neurons. $* P<0.05$. 

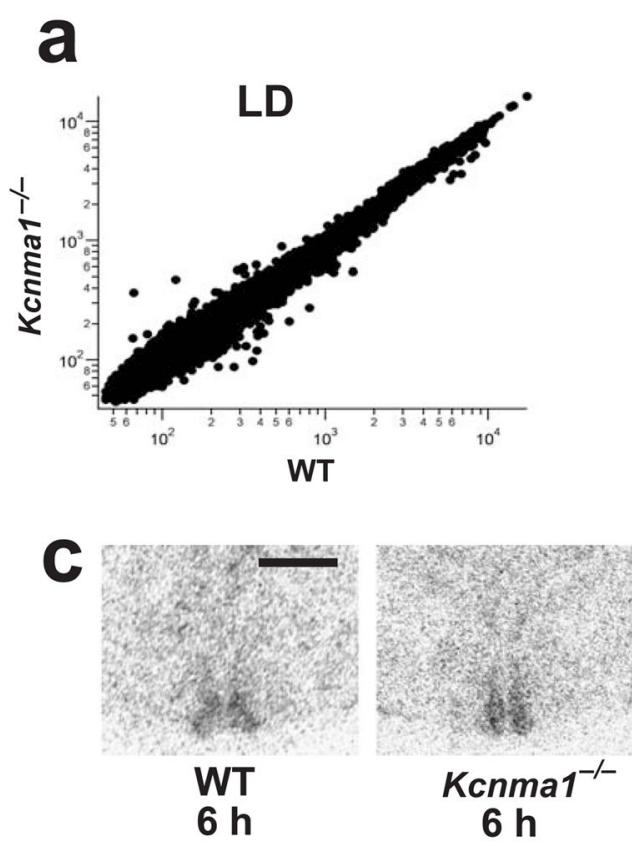
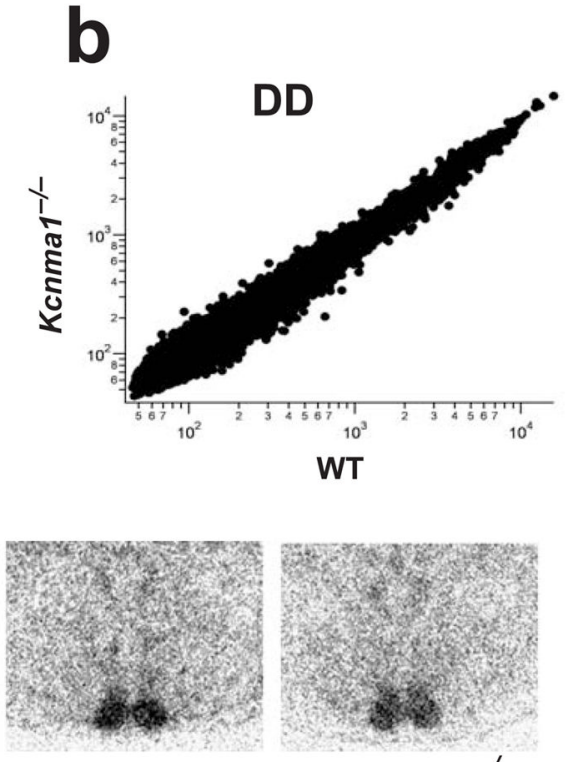

WT

$18 \mathrm{~h}$

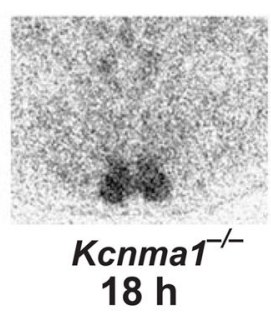

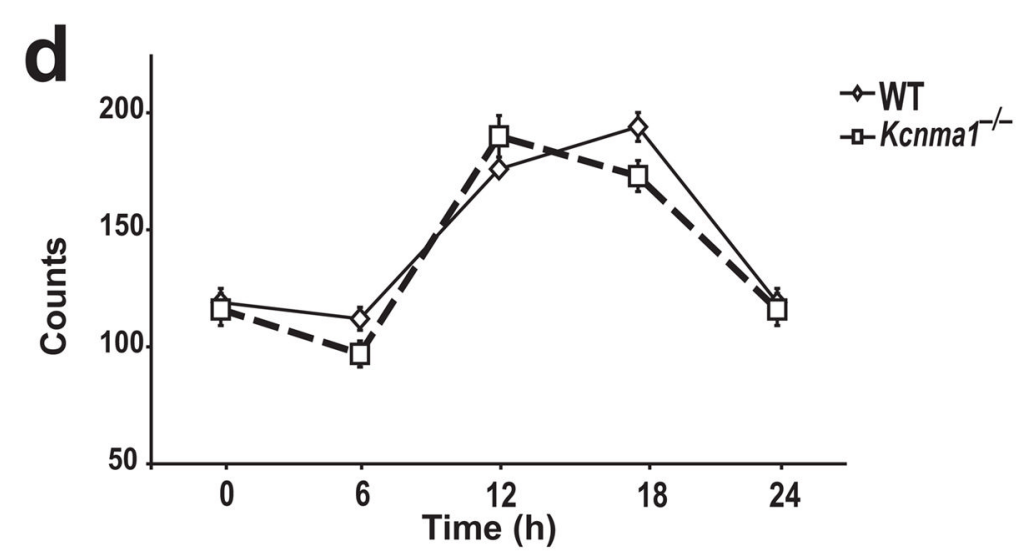

Figure 7.

Gene expression in the SCNs of $\mathrm{Kcnmal}^{-/-}$and wild-type mice. (a,b) Representative $\mathrm{Kcnmal}^{-/-}$versus wild-type pairwise comparisons of hypothalamic transcript expression from light-dark and constant darkness conditions at 20 h. (c) Arntl expression detected by in situ hybridization of coronal SCN sections. Mice were housed in constant darkness and brains were harvested at the indicated time point. Scale bar, 500 $\mu \mathrm{m}$. (d) Arntl expression was averaged between right and left SCNs, and counts were normalized to background expression in the hypothalamus and then averaged together into a group value \pm s.e.m. $P=$ 0.03 at $18 \mathrm{~h}$. 


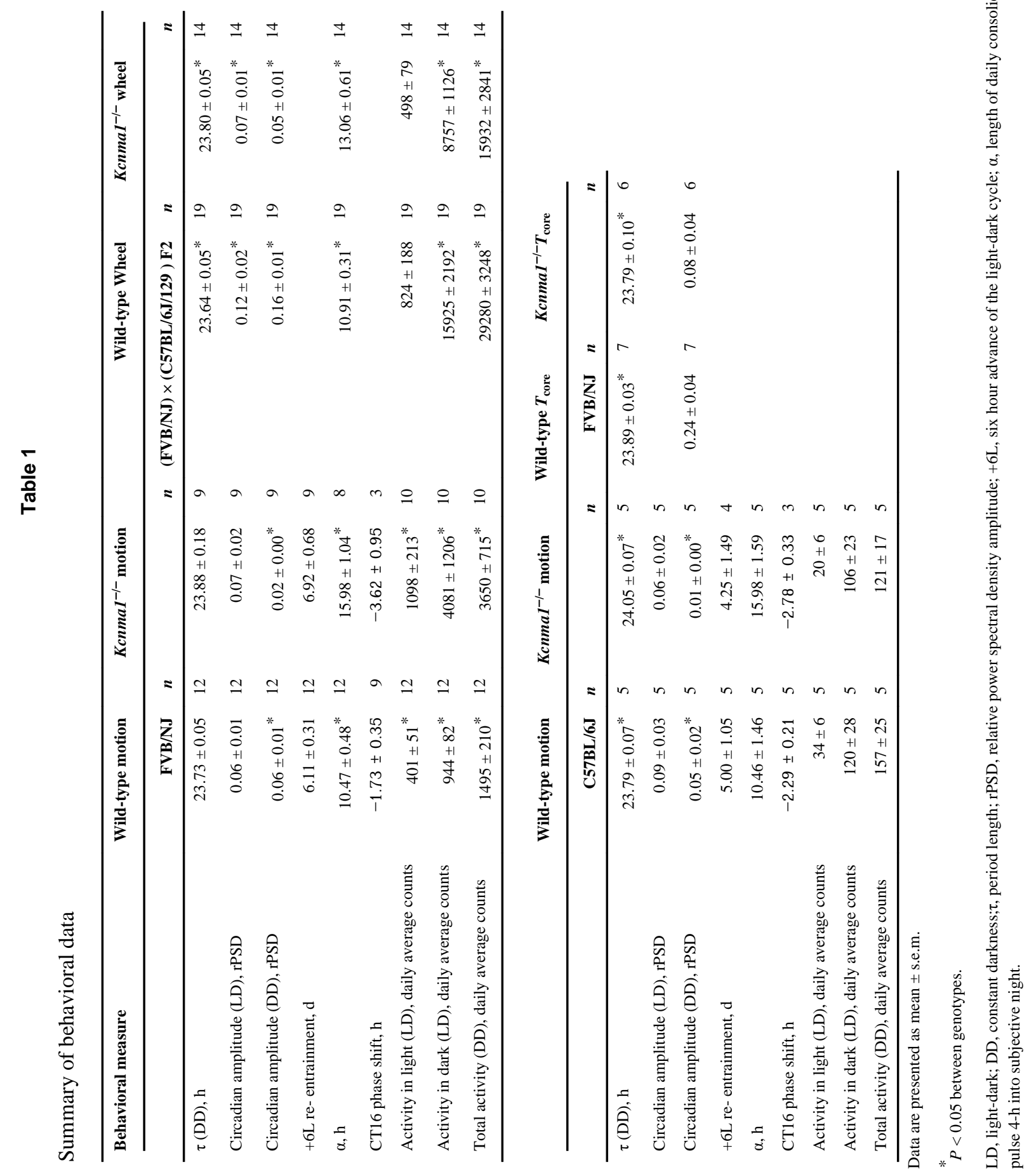

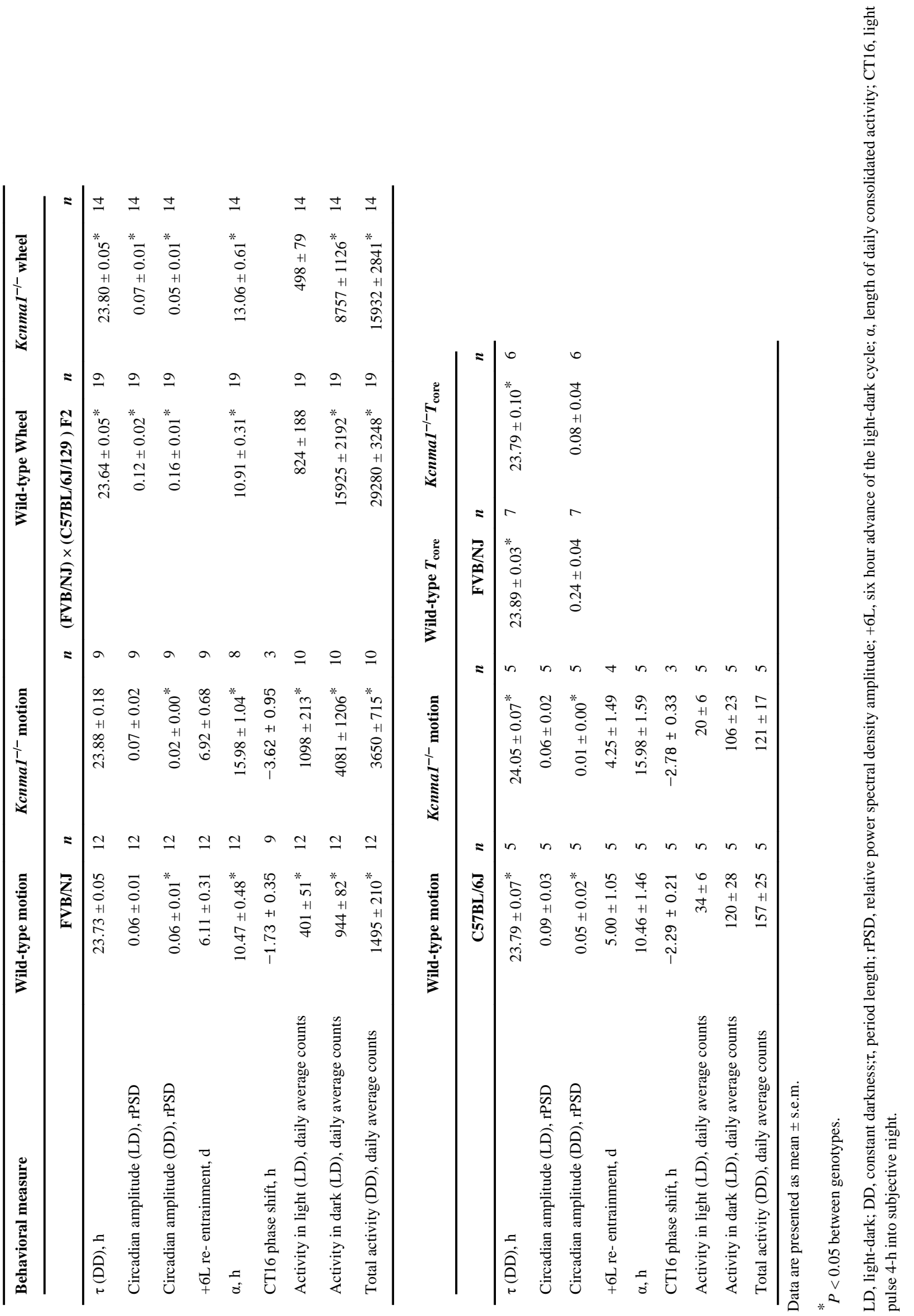

